\title{
Biochar's effect on the ecosystem services provided by sandy-textured and contaminated sandy soils: a systematic review protocol
}

\author{
Madina Bekchanova ${ }^{1 *} \mathbb{D}$, Luca Campion', Stephan Bruns ${ }^{1}$, Tom Kuppens ${ }^{1,3}$, Marijke Jozefczak², \\ Ann Cuypers $^{2}$ and Robert Malina ${ }^{1}$
}

\begin{abstract}
Background: Biochar is a relatively new soil amendment method in agricultural practices that can improve the ecosystem services of soils. Biochar has commonly been applied to less fertile or contaminated soils, specifically sandy-textured and contaminated sandy soils, to improve their properties. However, the available literature indicates that not all sandy-textured and contaminated sandy soils show the same response to biochar applications, as the sign and size of the effect vary across studies. More specifically, primary studies show heterogeneous and potentially conflicting impacts of biochar application on a set of ecosystem services provided by these types of soils; namely, biomass production, water cycle, nutrient cycle, and climate regulation. Therefore, the objective of the present study is to systematically review the available evidence base to synthesise the impact and drivers of biochar amendments on four specific ecosystem services provided by sandy-textured and contaminated sandy soils.

Methods: This review follows the guideline of the Collaboration for Environmental Evidence and corresponds to the ROSES (RepOrting standards for Systematic Evidence Synthesis) reporting standard. A comprehensive search strategy will be employed to cover peer-reviewed and gray literature through bibliographic databases, organizational and institutional websites, and web searches. Search terms and strategies have been developed to identify the impact of biochar on the ecosystem services of sandy-textured soils. The search results will be screened first by their title and abstract, and then by their full text. Two literature reviewers will do this based on eligibility criteria. A validity assessment will be conducted to critically appraise and assess the validity of studies using a common validity framework for environmental studies. Data will be extracted from the studies that are found to be valid for the review. Narrative synthesis and meta-analysis will be employed to synthesise the review results.
\end{abstract}

Keywords: Nutrient cycle, Crop production, Biomass production, Climate regulation, Water cycle, Residual biomass, Soil amendment

\section{Introduction}

\section{Background}

Sandy-textured and contaminated soils are marginal soils [1], which are characterized as poor-fertile soils due to

*Correspondence: madina.bekchanova@uhasselt.be

${ }^{1}$ Environmental Economics Group, Center for Environmental Sciences (CMK), Hasselt University, Diepenbeek, Belgium

Full list of author information is available at the end of the article low soil organic carbon [2], poor aggregate stability, and low water-holding capacity [3]. Sandy-textured soils can be in the forms of both natural and non-natural. Approximately $6 \%$ of the earth's surface (900 million hectares) consists of natural sandy soils [2], some of which are being intensely used for cultivation in developing countries, such as in Africa [4]. Non-natural sandy-textured soils are mainly the consequences of intensive agricultural practices and climate change [5-7]. For instance,

c) The Author(s) 2021. This article is licensed under a Creative Commons Attribution 4.0 International License, which permits use, sharing, adaptation, distribution and reproduction in any medium or format, as long as you give appropriate credit to the original author(s) and the source, provide a link to the Creative Commons licence, and indicate if changes were made. The images or other third party material in this article are included in the article's Creative Commons licence, unless indicated otherwise in a credit line to the material. If material is not included in the article's Creative Commons licence and your intended use is not permitted by statutory regulation or exceeds the permitted use, you will need to obtain permission directly from the copyright holder. To view a copy of this licence, visit http://creativeco mmons.org/licenses/by/4.0/. The Creative Commons Public Domain Dedication waiver (http://creativecommons.org/publicdomain/ zero/1.0/) applies to the data made available in this article, unless otherwise stated in a credit line to the data. 
intensive farming can negatively impact soil organic matter and nutrient levels, which can cause modifications in soil composition, rendering fertile soil marginal $[8,9]$. Likewise, climate change, such as global warming, affects the water cycle in the soil and the dynamics of soil moisture, which contributes to the conversion of fertile soils to sandy ones [10]. If the quality of sandy-textured, non-natural soils were at their original productive level, they could provide one-third of the world's population with basic food needs [7]. Furthermore, many agricultural soils are contaminated with heavy metal pollution because of unsustainable soil management, industrial activities, and the use of inorganic fertilizers and pesticides. These marginal soils, sandy-textured and contaminated sandy soils, rely heavily on external inputs such as organic and inorganic fertilizers to bring the soil productivity back and consequently conduct farming [11]. However, the long-term application of inorganic fertilizers negatively impacts the existing soil microbial communities and biochemical process, leading to the possible complete loss of soil fertility [12]. This is an issue particularly against the background of rapidly increasing human populations, which requires additional food production and, consequently, to some extent, additional arable land [13]. This, in turn, increases the need for environmentally sound technologies such as biochar that can improve soil quality and fertility.

Biochar is a relatively new development in agricultural management [14] that caught the attention of scientists as a means of environmental and sustainable soil management that can help increase the amount of land suited for agriculture [15-17]. Biochar can be defined as "solid material obtained from the thermochemical conversion of biomass in an oxygen-limited environment" [18]. Biochar is usually attained through pyrolysis of different types of organic feedstock, precisely biomass materials (plantations that produce energy crops, natural vegetable growth, organic wastes and residues (animal wastes, forest residue, agricultural residue, etc.) [19]) in varying pyrolysis degrees [16]. The conceptual paper titled "A handful of carbon" by Johannes Lehmann, published in 2007, was a turning point in biochar-related research [15]. The annual number of publications concerning biochar for environmental management has been increasing ever since $[15,20]$. The main topics covered in publications are the use of biochar in agriculture, waste management, energy production, and greenhouse gas reduction [15]. The agricultural benefits of biochar and its ability to reduce greenhouse gases are the most researched topics [15].

Biochar as a soil additive can enhance soil properties [21]. Biochar contributes to altering soil characteristics, resulting in positive modifications in water and nutrient retention capacity, soil aeration [22], as well as improving soil biological [23], chemical, and physical activities [24]. However, a recent review by Zhu and Chen [25] indicated the potential toxicity that can be induced to soil microbial communities with biochar application due to certain reactive compounds and heavy metals in the content of biochar. This leads to a change in soil microbial habitat, which could harm the soil and its ecosystem services [25]. The Millennium Ecosystem Assessment defines ecosystem services as "the benefits people obtain from ecosystems," classifying them into provisioning, regulating, cultural services, and supporting functions [26] (see Additional file 2). Jónsson and Davíðsdóttir [27] conducted a comprehensive review on soil ecosystem services (see Additional file 3), which will be employed for this review. Biochar is seen as a method of enhancing the status of soil ecosystem services [25], leading to increased crop and biomass productivity, sequestering additional carbon to mitigate climate change [28, 29], improving water retention of sandy-textured soils [16], and enhancing nutrient cycle by increasing soil nutrient availability and uptake [30].

Not all types of soil benefit from biochar applications to the same extent [31]. Alkaline soils in temperate climates have mainly responded to biochar addition transiently, especially with regard to crop productivity [32], and resulted in lower crop yields in high fertile soils [33]. However, less fertile, sandy, degraded, heavy-metal-polluted, and nutrient-deprived soils are more likely to benefit from biochar amendments [28, 34]. Even for these types of soils, the effects of biochar application for soil ecosystem can vary in sign and effect. For instance, some primary studies reported an increase in yield and nutrient retention of sandy loam soils using biochar prepared from manure, wood, and straw feedstocks [30, 35]. In contrast, some studies showed no change in crop yields when biochar from similar raw materials was applied on soils of the same type [36, 37]. Variation in results was also found with regard to the pyrolysis temperature. For example, higher pyrolysis temperature was preferred for the water retention capacities of sandy loam soils in the studies carried out by the researchers in the domain $[38,39]$. Wiersma, van der Ploeg [40] found no impact on water retention capacities for biochar produced at a similar pyrolysis temperature. Additionally, the application rate of biochar can also contribute to the heterogeneity in the outcome. Studies carried out in the field [41, 42] showed negative responses in crop productivity for lower application rate of biochar, whereas Rondon and Lehmann [43] found the opposite.

The apparent heterogeneity in results in the literature motivated us to conduct a systematic review to clarify the biochar's effect on ecosystem services, focusing 
specifically on natural and non-natural sandy-textured soils and contaminated soils. Based on our expertisebased understanding of the most important soil ecosystem services impacted by biochar application and on additional advice from the advisory committee for this systematic review, we specified the following supporting, regulation, and provisioning soil ecosystem services to be reviewed in this study: nutrient cycling, water cycling, climate regulation, and biomass/crop production. Review results can be exploited as complementary information by policymakers to facilitate policy recommendations of biochar applications as a soil amendment. Our review also aims to determine research gaps in current studies and set out a roadmap for further research related to biochar application on sandy-textured and contaminated soils.

\section{Stakeholder engagement}

The plan for a systematic review of biochar's effect on soil ecosystem services was brought forward in a project meeting of the BASTA project funded by the Research Foundation Flanders in December 2019 (BASTA: "Biochar's added value in sustainable land use with targeted applications") [44]. The BASTA project's main aim is the production of biochar from various residual biomasses and its application in different agricultural settings (biochar application in composting, anaerobic digestion, manure storage, growing media, and open field). BASTA stakeholders (academia, biochar producers, research institutes, agencies, policymakers) are aware of the lack of systematic synthesis on biochar's soil ecosystem services, and they support the systematic review.

An advisory committee was created, including some of the BASTA project members, with expertise in soil ecology, and with external ecosystem-services experts from the University of Hasselt. The advisory committee helped define the list of ecosystem services to review in the study. The members also contributed to the creation of search terms and search databases. Based on their suggestions, subsections such as data coding and extraction strategy and effect modifiers were improved.

\section{Objective of the review}

This paper's primary focus is to systematically review and synthesize studies on the effect of biochar on a set of four ecosystem services of sandy and contaminated sandy soils. To this end, the following research question has been formulated:

- What is the impact of biochar amendments on nutrient cycling and water cycling, climate regulation and crop/biomass production ecosystem services provided by sandy-textured and contaminated sandy soils?

The research question components were structured based on the PICO (population, intervention, comparator, outcome) model. The population in this study consists of soil types (sandy-textured soils and contaminated sandy soils). The intervention considered is the soil amendment using biochar, where the control of no biochar amendment serves as the comparator. Finally, the outcome is a positive, negative, or no change in sandytextured and contaminated sandy soils' four ecosystem services, which will be measured by comparing the treatment (with biochar) to control (without biochar). Potential effect modifiers that can affect the variation in the outcome will also be considered.

As mentioned earlier, for this review study, soil ecosystem services classified by Jónsson and Davíðsdóttir [27] will be adopted: supporting services (nutrient cycle, water cycle), regulating services (climate regulation), provisioning services (crop/biomass production) (see Additional file 3$)$.

Three types of soils with high levels of sand (more than $50 \%$ ) will be considered in the review, using the soil texture categorization (Table 1) by the United States Department of Agriculture [45]. Sandy-textured soils considered for the study are mainly degraded soils due to unsustainable agricultural activities, industrialization, and urbanization. Heavy-metal-contaminated sandy soils will also be considered for the review. One reason for selecting sandy-textured and contaminated sandy soils for this review is to provide supplementary information to the BASTA project that will implement experiments on these

Table 1 Soil types chosen for the study

\begin{tabular}{lllll}
\hline Common names of soils & Sand (\%) & Silt (\%) & Clay (\%) & Textural class \\
\hline Sandy soils (Coarse textured) & $86-100$ & $0-14$ & $0-10$ & Sand \\
& $70-86$ & $0-30$ & $0-15$ & Loamy sand \\
Loamy soils (Moderately coarse textured) & $50-70$ & $0-50$ & $0-20$ & Sandy loam \\
Loamy soils (Moderately fine texture) & $45-80$ & $0-28$ & $20-35$ & Sandy clay loam \\
\hline
\end{tabular}


types of soils in the Kempen region of Belgium. Furthermore, we will only consider biochar experiments on topsoil for this review, mainly due to the fact that many biochar-related studies implemented the experiments on topsoil (0-30 cm of soil depth). In addition, the scope of this study also lays on reviewing the changes in topsoil ecosystem services with biochar application. Review results will provide background information about the interaction between biochar and sandy-textured and contaminated sandy soils and the effect on four specific soil ecosystem services that can be beneficial for further analysis of ecosystems of soils chosen for the BASTA project.

\section{Geographical scope}

After testing the search terms (Table 2) in WoS, we obtained 2382 results. Ninety randomly selected hits were used to screen title and abstract to determine the regions in which studies were carried out the most. Based on this random sampling, we found out that studies were carried out in many different regions, so we decided not to impose any geographical scope in order to ensure sufficient data. Geographical locations where experiments were carried out will be considered as an effect modifier.

\section{Methods}

The review protocol will follow the guidelines of the Collaboration for Environmental Evidence [46] and corresponds with the ROSES [47] reporting standard. The ROSES form is included as an Additional file 1.

\section{Searching for articles \\ Search string}

The search terms will be based on the PICO components. Three components of PICO (population, intervention, and outcome) will be combined to build search terms. For field tags, TS (TITLE-ABS-KEY) will be used. Component categories between search terms will be merged using the "AND" Boolean operator, while "OR" operators will be used within categories. Truncation characters (" and \$) will also be used to make the search more expansive. To come up with search strings (Table 2), an initial scoping exercise was carried out on the Web of Science (WoS) "Core collection" database. For the scoping exercise, we first specified terms for four specific soil ecosystem services by applying the terms defined by Jónsson and Davíðsdóttir [27]. The advisory group then helped to complement the final search terms with related synonyms. The search terms in Table 2 are considered as definite. To conduct the scoping exercise in the advanced search function of WoS "Core collection", we have used the institutional subscription of the Hasselt University library.
The search terms have been designed to retrieve all publications on biochar's effect on nutrient cycle, water cycle, climate regulation, and crop/biomass yield of sandy-textured and contaminated sandy soils. All documents, including peer-reviewed publications and gray literature (not submitted to peer-reviewed journals), will be retrieved to minimize publication bias [48]. To maximize the search, the following sources will be searched: bibliographic databases (for peer-reviewed publications), organizational/institutional websites, and webbased searches (for gray literature, which can include publications, organizational reports, theses, etc.). Search terms displayed in Table 2 are mostly applicable for bibliographic databases as they have more advanced search functions. When the search terms are applied to organizational websites and internet-based searches, the search formula and Boolean operators can be simplified because they might have limited search interfaces regarding search strings. All of the used search strings will be saved and provided as additional information in the final report.

\section{Search language}

The search will be carried out in English, and search results in languages other than English will not be considered for the review. English is the common language among the review team, so it will provide dual consistency checking in screening, full-text review, quality appraisal, and data extraction.

\section{Evaluating search comprehensiveness}

To ensure the comprehensiveness of the search strings built for the review (Table 2), the search strings were tested against a set of 15 benchmark articles (see Additional file 4). The bibliographies of benchmark articles were also screened to check whether relevant articles cited were contained in the search results. When search results were found to not be pertinent, and any missing articles were detected, the final search strings were modified accordingly. The set of benchmark articles is generated by searching the publications of highly cited and relevant articles.

\section{Bibliographic databases}

The following bibliographic databases will be searched to collate publications by using the advanced search tools of databases.

- Web of Science "Core collection": https://www.webof knowledge.com.

- Scopus: https://www.scopus.com/.

- AGRICOLA: https://www.agricola.nal.usda.gov/.

- AGRIS: https://www.agris.fao.org/. 


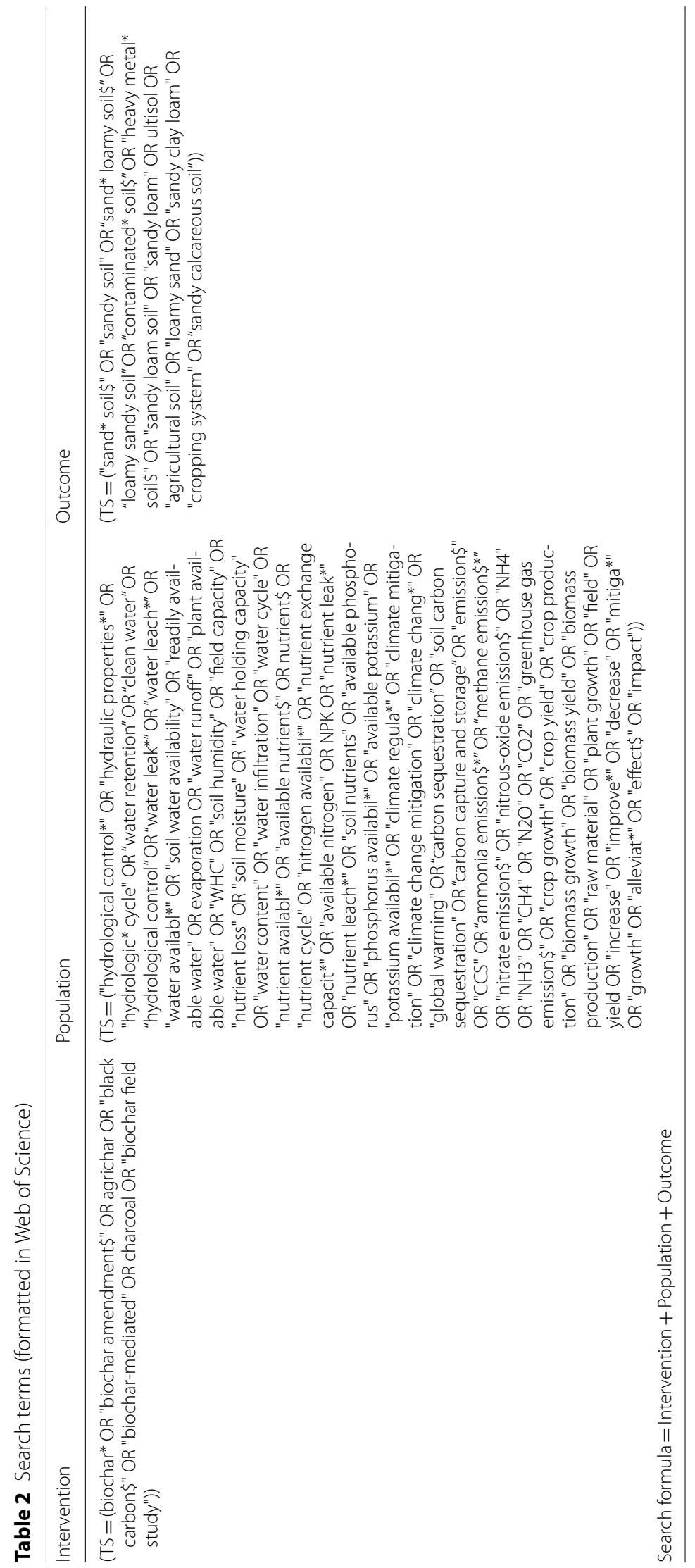


- ProQuest Environmental Sciences and Pollution Management: https://search.proquest.com/advan ced.

- EBSCO Open Dissertations: https://biblioboard. com/opendissertations/.

- Networked Digital Library of Theses and Dissertations: http://www.ndltd.org/.

- Open access theses and dissertations: https://oatd. org/.

\section{Organizational websites}

The following organizational websites will be searched to obtain potential additional studies that are not covered by the bibliographic databases. As mentioned above, some organizational websites might not have a very advanced search function. Therefore, some manual searches will be executed using the search terms defined in Table 2.

- International Biochar Initiative: https://biochar-inter national.org/biochar/.

- UK Biochar Research Center: https://www.biochar. ac.uk/research.php?id=10\&r=a.

- US Biochar Initiative: https://biochar-us.org/biocharintroduction.

- European Biochar Certificate: https://www.europ ean-biochar.org/en/home.

- Sonoma Biochar Initiative: https://sonomabiocharin itiative.org/.

- Israel Biochar Research Network: https://sites.google. com/site/ibrnisraelbiocharnetwork/home.

- Biochar for sustainable soils: https://biochar.inter national/.

- Ithaka institute: http://www.ithaka-institut.org/en/ home.

- New Zealand Biochar Research Centre: https://www. massey.ac.nz/massey/learning/colleges/college-ofsciences/research/agriculture-environment-research/ biochar-research-centre/biochar-research-centre home.cfm.

- Environmental Protection Agency (USA): https:// www.epa.gov/.

- Research Institute for Organic Agriculture: https:// knowledge4policy.ec.europa.eu/organisation/resea rch-institute-organic-agriculture_en.

- Research Institute for Agriculture, Fisheries and Food (ILVO, Belgium, Flanders): https://www.ilvo.vlaan deren.be/EN/Home.

- Netherlands Organisation for Applied Scientific Research (TNO, The Netherlands): https://www.tno. $\mathrm{nl} / \mathrm{en} /$.
- Wageningen University \& Research (The Netherlands): https://www.wur.nl/en/wageningen-unive rsity.htm.

- Julius Kühn Institute-Federal Research Centre for Cultivated Plants (Germany): https://www.juliuskuehn.de/en/.

- Mercator Research Institute on Global Commons and Climate Change (Germany): https://www.mccberlin.net/en/index.html.

- Thünen institute-Federal Research Institute for Rural Areas, Forestry and Fisheries (Germany): https://www.thuenen.de/en/about-us/the-institute/.

- Agroscope (Switzerland): https://www.agroscope. admin.ch/agroscope/en/home.

- James Hutton Institute (United Kingdom): https:// www.hutton.ac.uk/.

- Rothamsted Research (United Kingdom): https:// www.rothamsted.ac.uk/.

- UK Centre for Ecology \& Hydrology (United Kingdom): https://www.ceh.ac.uk/.

\section{Web-based searches}

In addition to the bibliographic database and organizational website searches, web-based searches will be conducted using Google (https://www.google.com/) and Google Scholar (https://scholar.google.com/). Google Scholar will be used to retrieve both peer-reviewed and gray literature [49]. Google Scholar is not recommended as a standalone resource in a systematic review, but it can be valuable for complementing bibliographic searches and retrieving full texts of articles in PDF [49]. Google searches can be broad and return many results for every search, both related and unrelated to the review objective. For that reason, in our review study we will download the first 1000 results returned by Google scholar [50] using Publish or Perish software [51] as also done, for example, by other systematic reviews in Environmental Evidence [52, 53]. The software will assist in retrieving relevant articles to add to the reference list in Endnote. We will also account for the reference lists of relevant articles for the supplemental searches.

\section{Search record database}

The Endnote X9 reference management software will be used to import the search results. If a certain document cannot be imported into the software, a record will be managed manually by creating a separate file. After finalizing all searches, the reference files will be merged and checked for duplicates. Before removing any of the duplicates, they will be rechecked and compared with regard to title, abstract, and year of publication. Once all 
duplicates have been removed, the final version will be checked with Endnote's deduplication tool.

\section{Article screening and study eligibility criteria Screening process}

The screening processes will encompass two steps and will be conducted by two reviewers. The first two authors of this review protocol make up the review team that will carry out all review steps (such as eligibility criteria and critical appraisal). In the first step, the results are filtered screening on their title together with abstract relevance. In the second step, selected articles will be reviewed for their full text. Systematic reviewers who have also authored articles to be considered in the review cannot get assigned to assess their own work. The screening will be based on the eligibility criteria provided in the following section.

Before starting the actual screening, both reviewers will screen 100 randomly chosen articles from the search results to ensure consistency regarding decisions about the inclusion criteria. Consistency checking will be conducted at each stage of the screening. If the reviewer has any doubt about excluding a paper, it should be marked and discussed later with the other reviewer. Upon mutual agreement, the publication will be excluded or not. If reviewers cannot reach a consensus about inclusion, the publication will be reviewed by an adjudicating reviewer. The level of agreement regarding consistency will be verified by employing the Kappa statistic [54]. According to the Kappa statistic, agreements should not be below 0.6, otherwise, consistency testing will be repeated until a higher agreement is attained. All disagreements will be discussed in detail between reviewers prior to starting the actual screening. Any excluded article at the full-text screening step will be recorded, together with an explanation for the exclusion in the appendix of the final report.

\section{Eligibility criteria}

As mentioned above, the eligibility criteria will be based on the PICO model.

Population Regarding eligible populations, studies performing experiments on soils other than sandy-textured and contaminated sandy soils (see Table 1) will be excluded. If the type of soils upon which an experiment was performed are not defined, the corresponding authors will be contacted. If it is not possible to clarify in any other way, those studies will be excluded. Furthermore, studies implemented in the experiments on topsoil $(0-30 \mathrm{~cm})$ will be considered for the review. Deep-soil experiments will be excluded as they are beyond the scope of the review.
Intervention The eligible intervention is biochar, produced from biomass, used in agriculture as a soil amendment. Some studies use terms like charcoal and black carbon as a synonym of biochar. However, black carbon and charcoal can differ from biochar in production and application purposes. For instance, black carbon can be made by burning fossil fuels as well as biomass [55], while charcoal is produced mainly to provide affordable energy to rural areas and is not used solely as a soil amendment [56]. However, we do include the terms "black carbon" and "charcoal" in the intervention search terms (Table 2). We will bring the terms ("black carbon" and "charcoal") into the full-text level to confirm that they are indeed made of organic feedstocks and have the same application intention as biochar. Otherwise, studies included the terms "black carbon" and "charcoal" will be excluded at the full stage of screening. We will also use the term Agrichar, as it is a new term that is used in some organizational websites and is closely related to biochar.

Comparator Control sites or plots without any intervention-that is, no biochar added or treated as the intervention plots-will be used as a comparator. However, control sites or plots that are treated with fertilizers will also be included. In the latter case, intervention plots should have been managed with biochar together with fertilizers to make it comparable.

Outcomes Outcomes considered for the review are positive, negative, or no changes in four ecosystem services (nutrient cycling, water cycling, climate regulation, and biomass/crop production) of sandy-textured and contaminated sandy soils.

Study design types Experimental primary studies, particularly laboratory experiments, greenhouse experiments, and field experiments that employed control and treatment groups, will be included in the review. Previously systematically reviewed papers will also be accounted for by screening their reference lists.

\section{Study validity assessment}

Studies that meet the eligibility criteria will be critically appraised to assess their internal and external validity. Critical appraisal is a critical stage of the systematic review in terms of evaluating the studies' suitability for the data synthesis. Studies that are found to be eligible will be appraised for the different types of biases by being categorized as "low", "moderate", and "high" risk of bias (see Additional file 5). The factors in Table 3 are selected for the critical appraisal. 
Table 3 Critical appraisal criteria

\begin{tabular}{|c|c|c|c|}
\hline Factor & Low risk of bias & Moderate risk of bias & High risk of bias \\
\hline Study design & $\begin{array}{l}\text { Experimental studies (treatment vs } \\
\text { control) }\end{array}$ & $\begin{array}{l}\text { Quasi-experimental studies (including } \\
\text { concurrent controls) }\end{array}$ & Case studies and observational studies \\
\hline Objectives/hypothesis & $\begin{array}{l}\text { Clear relation between objectives and } \\
\text { methodology }\end{array}$ & $\begin{array}{l}\text { Clear relation between objectives and } \\
\text { methodology }\end{array}$ & $\begin{array}{l}\text { No relation between objectives and } \\
\text { methodology }\end{array}$ \\
\hline \multirow[t]{4}{*}{ Sampling } & $\begin{array}{l}\text { Sampling method is suitable for gather- } \\
\text { ing data on the population of interest }\end{array}$ & $\begin{array}{l}\text { The method used for sampling is } \\
\text { appropriate for data gathering on } \\
\text { population of interest }\end{array}$ & \multirow[t]{4}{*}{$\begin{array}{l}\text { Sampling method is not suitable for the } \\
\text { population of interest }\end{array}$} \\
\hline & $\begin{array}{l}\text { Replicates are proper (interventions are } \\
\text { replicated) }\end{array}$ & Replicates are proper & \\
\hline & $\begin{array}{l}\text { Intervention and comparator areas are } \\
\text { well-matched (soil conditions are the } \\
\text { same) }\end{array}$ & $\begin{array}{l}\text { Intervention and comparator areas are } \\
\text { well-matched (soil conditions do not } \\
\text { differ profoundly) }\end{array}$ & \\
\hline & $\begin{array}{l}\text { Confounding factors not present (both } \\
\text { intervention and comparator sites are } \\
\text { treated equally) }\end{array}$ & $\begin{array}{l}\text { Confounding factors not present (both } \\
\text { intervention and comparator sites are } \\
\text { treated equally) }\end{array}$ & \\
\hline $\begin{array}{l}\text { Consideration of } \\
\text { heterogeneity/effect } \\
\text { modifiers }\end{array}$ & $\begin{array}{l}\text { Precisely determined/considered effect } \\
\text { modifiers }\end{array}$ & Effect modifiers are considered & $\begin{array}{l}\text { Effect modifiers not considered or } \\
\text { determined }\end{array}$ \\
\hline Statistical analysis & $\begin{array}{l}\text { Clear description of statistical analysis } \\
\text { and results }\end{array}$ & $\begin{array}{l}\text { Statistical analysis and results are clear } \\
\text { enough }\end{array}$ & $\begin{array}{l}\text { Not appropriate statistical analysis and } \\
\text { results }\end{array}$ \\
\hline
\end{tabular}

The criteria in Table 3 is created based on a framework suggested by Bilotta, Milner [57] and the critical appraisal tool developed by CEE [58] to assess the internal validity of the studies and consider all possible biases (selection bias, performance bias, attrition bias, reporting bias, etc.). Studies with a "low "and "moderate" risk of bias will be used to extract necessary data for data synthesis, while publications found to have a "high" risk of bias will be used to conduct a sensitivity analysis by comparing the outcome of including and excluding the papers with "high" risk of bias. If studies are appraised as having a "moderate" risk of bias due to missing data, the corresponding authors will be contacted; otherwise, they will be used in a narrative synthesis. All information related to the risk assessment and excluded studies at the stage of a critical appraisal will be recorded in the database and presented with the final review results.

As with screening, consistency checking will also be done for the critical appraisal. Again, all studies will be evaluated by the same two appointed reviewers. If there are disagreements regarding any of the criteria, the study will be discussed between reviewers until a consensus is reached. If this is not possible, a third reviewer will be involved.

\section{Data coding and extraction strategy}

In our review, we analyze the effect of biochar on different ecosystem services (nutrient cycling, water cycling, climate regulation, and biomass/crop production). Therefore, each included study may report estimates for different ecosystem services. Moreover, each study may report multiple estimates for the same ecosystem service. We extract all these estimates from the studies and place them into individual rows. We address the potential dependence of the data as outlined below in the "Data synthesis and presentation" section.

In case of a misunderstanding or any missing data, authors will be contacted to clarify and obtain the missing data. All extracted data from included studies will be saved in a Microsoft Excel spreadsheet, which will be attached as an additional file for the final review. Table 4 shows the essential data for the extraction process. If the data are presented only in tables or graphs, they will be extracted using apps like webplotdigitizer, and the information will be recorded in the spreadsheet. If the data are hard to extract or decipher, or if data are missing, then the corresponding author of the article will be contacted for more clarification or submission of data. The same procedure will be followed in the data synthesis stage. In case the required data cannot be obtained, the studies will be excluded from the analysis. Extracted data records and excluded studies will be made available as an additional file.

To check the consistency of the coding, the same method will be applied as for screening and quality appraisal. Ten percent of randomly selected papers will be used by each reviewer for consistency of coding.

\section{Potential effect modifiers/reasons for heterogeneity}

If there are any effect modifiers that may cause heterogeneity in the outcome, they will be retrieved and recorded in an Excel spreadsheet. Below, a list of effect 
Table 4 Data coding

\begin{tabular}{|c|c|c|c|}
\hline \# & Category & Variable & Description \\
\hline \multirow[t]{3}{*}{1} & \multirow[t]{3}{*}{ Study ID } & First author & Mainly last name of the first author \\
\hline & & Publication year & Year the article is published \\
\hline & & Numbering & Code for each data point in the study \\
\hline 2 & Name of research group & Research group & $\begin{array}{l}\text { Listing the research group that implemented the } \\
\text { research and experiment }\end{array}$ \\
\hline 3 & Validity of a study & Validity of a study & $\begin{array}{l}\text { Internal and external validity of a study that will be } \\
\text { assessed as "low","moderate" or "high" risk of bias }\end{array}$ \\
\hline \multirow[t]{2}{*}{4} & \multirow[t]{2}{*}{ Type of paper } & Peer-reviewed & If the paper is published in a peer-reviewed journal \\
\hline & & Gray literature & $\begin{array}{l}\text { If it is a publication in a website, or a dissertation/thesis, } \\
\text { or conference summaries }\end{array}$ \\
\hline \multirow[t]{5}{*}{5} & \multirow[t]{5}{*}{ Study location } & Study area & The area where the study has been conducted \\
\hline & & Longitude and latitude & The longitude and the latitude of study area \\
\hline & & Country & The country where the study area is located \\
\hline & & Type of climate & Classification of climate of the country \\
\hline & & Average precipitation & Expressed in mm: Average precipitation in study area \\
\hline \multirow[t]{6}{*}{6} & \multirow[t]{6}{*}{ Experimental condition } & Condition & Listing if it is randomized replicates or different \\
\hline & & Experimental design & If it is based on open field, greenhouse, or lab \\
\hline & & Design characteristics & $\begin{array}{l}\text { Plot area, number of plots, or pots (if it is greenhouse or } \\
\text { lab experiment) }\end{array}$ \\
\hline & & Experimental setup & $\begin{array}{l}\text { Control (without amendment, or with fertilizer or with } \\
\text { manure), treatment (with biochar, or fertilizer + bio- } \\
\text { char, or manure + biochar) }\end{array}$ \\
\hline & & Duration of experiment & Expressed in days \\
\hline & & Biochar application rate & Expressed in $\mathrm{t} / \mathrm{ha}$ \\
\hline \multirow[t]{3}{*}{7} & \multirow[t]{3}{*}{ Biochar properties } & Feedstock used & $\begin{array}{l}\text { The feedstocks used for pyrolysis will be grouped as } \\
\text { "woody biomass", "manure"," "peat-based", and "agricul- } \\
\text { tural residue" }\end{array}$ \\
\hline & & Pyrolysis temperature & Expressed in the Celsius scale \\
\hline & & Carbon rate & Expressed in $\mathrm{g}$ per $\mathrm{kg}(\mathrm{g} / \mathrm{kg})$ and mass percentage \\
\hline \multirow[t]{4}{*}{8} & \multirow[t]{4}{*}{ Soil status } & Type of soil & $\begin{array}{l}\text { Type of sandy soil and contaminated soil used for the } \\
\text { experiment }\end{array}$ \\
\hline & & Soil sample depth & $\begin{array}{l}\text { The minimum and maximum soil depth at which } \\
\text { biochar is applied; expressed in } \mathrm{cm}\end{array}$ \\
\hline & & Soil treatment before biochar & NPK fertilizer, manure, or other treatments \\
\hline & & Soil condition & Soil is tilled or irrigated before the experiment \\
\hline \multirow[t]{2}{*}{9} & \multirow[t]{2}{*}{ Ecosystem services (ESS) } & Measurement & List of ESS measured in the study \\
\hline & & Measurement unit & Unit used to measure ESS \\
\hline \multirow[t]{2}{*}{10} & \multirow[t]{2}{*}{ Changes in ecosystem services } & $\begin{array}{l}\text { Control (without amendment, or with manure, or with } \\
\text { fertilizer) }\end{array}$ & Means, SD, correlation, OR t-value OR F-score \\
\hline & & $\begin{array}{l}\text { Treatment (with biochar only, or with manure + bio- } \\
\text { char, or fertilizer + biochar) }\end{array}$ & Means, SD, correlation, OR t-value OR F-score \\
\hline
\end{tabular}

modifiers was collated in consultation with the advisory team. If additional effect modifiers are detected during the review, they will be added to the list. All effect modifiers will be coded and represented in the narrative analysis, and their effect on variation in the outcome will be explored through the meta-regression analysis. The potential effect modifiers are: study country, experimental design, experimental setup, climate type, duration of experiment, feedstock for biochar, biochar carbon rate, pyrolysis temperature, application rate of biochar, type of soil, soil depth, and soil treatment before biochar.

\section{Data synthesis and presentation}

A narrative synthesis will be generated to visually represent the data of all included studies with low risk of bias (see "Study validity assessment"). Data extracted from each study based on Table 4 and studies that do not have quantitative results (for example, no means, SD, 
or correlation) will also be used for the narrative synthesis. We will create tables to represent the countries where experiments were implemented, together with experimental conditions, types of experiments (control, treatment), and duration of experiments in a narrative manner.

We plan to conduct meta-analysis if there are a sufficient amount of quantitative data to be extracted. We use separate meta-analyses to assess the effect of biochar on four specific soil ecosystem services (nutrient cycling, water cycling, climate regulation, and biomass/crop production). We will conduct the meta-analysis in $R$ [59] using the metaphor package [60]. To measure the effect size (treatment to control) the natural log-transformed response ratio will be used [61], which is the favored method for calculating the effect size in ecological studies $[62,63]$. We will synthesize effect sizes by inverse-variance weighting to assign higher weights to more precise studies [64]. We will report results for fixed-effects and random-effects models. We potentially extract multiple estimates from the same study (for instance, multiple comparisons between the same plots or pots at different time points). We conduct the meta-analyses using the estimate that the authors of the study describe as the main results to address the potential dependence of estimates from the same study. Results using all estimates will be also reported. If data allow, sub-group analysis for important effect modifiers are conducted, such as different study designs (greenhouse, lab and field experiments).

In addition to subgroup analysis, we will explore how variation in the estimates can be explained by effect modifiers using a meta-regression. The meta-regression will help to shed light on which effect modifiers are the most important. The meta-regression will be conducted for all estimates (potentially multiple estimates per study) to allow for a maximum of variation in the estimates that can be then traced back to various effect modifiers. We account for dependency of the data by using standard errors that are clustered at the level of studies $[65,66]$. In case there is incomplete or missing data from any articles or data that cannot be obtained by contacting the corresponding authors, the studies will be excluded from the analysis. The list of excluded articles at the stage of datasynthesis will be recorded and reported as an additional file at the final review.

The presence of publication bias will be assessed by visual inspection of funnel plots, the Egger tests [67], and comparisons of studies published in journals with grey literature. Sensitivity analysis will be employed to test the robustness of the studied outcomes and the effect of validity assessment. This will be done by conducting analyses of the inclusion and exclusion of studies with a high risk of bias.

\section{Supplementary Information}

The online version contains supplementary material available at https://doi. org/10.1186/s13750-021-00223-1.

Additional file 1. ROSES form.

Additional file 2. Ecosystem services categorization.

Additional file 3. Soil ecosystem services.

Additional file 4. List of benchmark articles.

Additional file 5. Critical appraisal benchmark articles.

Additional file 6 . A draft version of data extraction and coding sheet.

\section{Acknowledgements}

This review study was supported by BASTA project and the authors would like to thank all stakeholders of the project who contributed to designing the review protocol. The authors would also like to thank Anne Nobel for helping to make the review topic more specific.

\section{Authors' contributions}

$M B$ and RM jointly designed the study. MB developed the first draft of the protocol. MB and RM took the lead in the revision of the protocol. All other authors contributed to the revisions of the protocol with their critical comments. All authors read and approved the final manuscript.

\section{Funding}

The review is implemented as part of Madina Bekchanova's Ph.D, which is funded through the BASTA project. Luca Campion is also receiving funding from the BASTA project. Funding was provided by Fonds Wetenschappelijk Onderzoek (S000119NBA).

Availability of data and materials

All data analyzed during this study will be included in this published article and its additional information files.

\section{Declarations}

Ethics approval and consent to participate

Not applicable.

Consent for publication

Not applicable.

Competing interests

The authors declare that they have no competing interests.

\section{Author details}

${ }^{1}$ Environmental Economics Group, Center for Environmental Sciences (CMK), Hasselt University, Diepenbeek, Belgium. ${ }^{2}$ Environmental Biology Group, Center for Environmental Sciences, Hasselt University, Diepenbeek, Belgium.

${ }^{3}$ Vrije Universiteit Brussel, Brussel, Belgium.

Received: 30 June 2020 Accepted: 20 March 2021

Published online: 31 March 2021

\section{References}

1. Jimin S, Zhongli D, Tungsheng L. Desert distributions during the glacial maximum and climatic optimum: example of China. Episodes-Newsmag Int Union Geol Sci. 1998;21(1):28-31.

2. Yost JL, Hartemink AE. Soil organic carbon in sandy soils: a review. Advances in agronomy. 2019:217.

3. Van Asperen H, Bor A, Sonneveld M, Bruins H, Lazarovitch N. Properties of anthropogenic soils in ancient run-off capturing agricultural terraces in the Central Negev desert (Israel) and related effects of biochar and ash on crop growth. Plant Soil. 2014;374(1-2):779-92. 
4. Hartemink AE, Huting J. Land cover, extent, and properties of Arenosols in Southern Africa. Arid Land Res Manag. 2008;22(2):134-47.

5. Mulcahy D, Mulcahy D, Dietz D. Biochar soil amendment increases tomato seedling resistance to drought in sandy soils. J Arid Environ. 2013;88:222-5.

6. Al-Wabel MI, Hussain Q, Usman AR, Ahmad M, Abduljabbar A, Sallam AS, et al. Impact of biochar properties on soil conditions and agricultural sustainability: a review. Land Degrad Dev. 2018;29(7):2124-61.

7. Kang S, Post WM, Nichols JA, Wang D, West TO, Bandaru V, et al. Marginal lands: concept, assessment and management. J Agric Sci. 2013;5(5):129.

8. Karim AZ. Impact of a growing population in agricultural resource management: exploring the global situation with a micro-level example. Asian Soc Sci. 2013;9(15):14.

9. Kumar R, Das AJ. Climate change and its impact on land degradation: imperative need to focus. J Climatol Weather Forecast. 2014. https://doi. org/10.4172/2332-2594.1000108.

10. Holsten A, Vetter T, Vohland K, Krysanova V. Impact of climate change on soil moisture dynamics in Brandenburg with a focus on nature conservation areas. Ecol Model. 2009;220(17):2076-87.

11. Uzoma K, Inoue M, Andry H, Zahoor A, Nishihara E. Influence of biochar application on sandy soil hydraulic properties and nutrient retention. J Food Agric Environ. 2011;9(3/4 part 2):1137-43.

12. Meena RS, Kumar S, Datta R, Lal R, Vijayakumar V, Brtnicky M, et al. Impact of agrochemicals on soil microbiota and management: a review. Land. 2020;9(2):34.

13. Kumar A, Bhattacharya T. Biochar: a sustainable solution. Environ Dev Sustain. 2020. https://doi.org/10.1007/s10668-020-00970-0.

14. Lehmann J, Gaunt J, Rondon M. Bio-char sequestration in terrestrial ecosystems - a review. Mitig Adapt Strat Glob Change. 2006;11(2):403-27.

15. Zhang C, Zeng G, Huang D, Lai C, Chen M, Cheng M, et al. Biochar for environmental management: mitigating greenhouse gas emissions, contaminant treatment, and potential negative impacts. Chem Eng J. 2019;373:902-22.

16. Razzaghi F, Obour PB, Arthur E. Does biochar improve soil water retention? A systematic review and meta-analysis. Geoderma. 2020;361:114055.

17. Agbede T, Odoja A, Bayode L, Omotehinse P, Adepehin I. Effects of biochar and poultry manure on soil properties, growth, yield and quality of cocoyam (Xanthosoma sagittifolium Schott) grown in sandy soil. Commun Soil Sci Plant Anal. 2020;51(7):932-47.

18. IBI. The Use of Biochar in Composting 2015. www.biochar-international. org.

19. Panwar N, Pawar A, Salvi B. Comprehensive review on production and utilization of biochar. SN Appl Sci. 2019;1 (2):168.

20. Lehmann J. A handful of carbon. Nature. 2007:447(7141):143-4.

21. Smith P, Adams J, Beerling DJ, Beringer T, Calvin KV, Fuss S, et al. Landmanagement options for greenhouse gas removal and their impacts on ecosystem services and the sustainable development goals. Annu Rev Environ Resour. 2019:44:255-86

22. Atkinson CJ, Fitzgerald JD, Hipps NA. Potential mechanisms for achieving agricultural benefits from biochar application to temperate soils: a review. Plant Soil. 2010;337(1-2):1-18.

23. Lehmann J, Rillig MC, Thies J, Masiello CA, Hockaday WC, Crowley D. Biochar effects on soil biota—a review. Soil Biol Biochem. 2011:43(9):1812-36.

24. Wang $D$, Jiang $P$, Zhang $H$, Yuan W. Biochar production and applications in agro and forestry systems: a review. Sci Total Environ. 2020;723:137775.

25. Zhu X, Chen B, Zhu L, Xing B. Effects and mechanisms of biochar-microbe interactions in soil improvement and pollution remediation: a review. Environ Pollut. 2017;227:98-115.

26. Millennium Ecosystem Assessment M. Ecosystems and human wellbeing. Synthesis. 2005.

27. Jónsson JÖG, Davíðsdóttir B. Classification and valuation of soil ecosystem services. Agric Syst. 2016;145:24-38.

28. Sohi SP, Krull E, Lopez-Capel E, Bol R. A review of biochar and its use and function in soil. Advances in agronomy. 105: Elsevier; 2010. p. 47-82.

29. Hansen V, Müller-Stöver D, Munkholm L, Peltre C, Hauggaard-Nielsen H, Jensen LS. The effect of straw and wood gasification biochar on carbon sequestration, selected soil fertility indicators and functional groups in soil: an incubation study. Geoderma. 2016;269:99-107.
30. Gao S, Hoffman-Krull K, Bidwell A, DeLuca T. Locally produced wood biochar increases nutrient retention and availability in agricultural soils of the San Juan Islands, USA. Agr Ecosyst Environ. 2016;233:43-54.

31. Ippolito JA, Laird DA, Busscher WJ. Environmental benefits of biochar. J Environ Qual. 2012:41(4):967-72

32. Borchard N, Siemens J, Ladd B, Möller A, Amelung W. Application of biochars to sandy and silty soil failed to increase maize yield under common agricultural practice. Soil Tillage Res. 2014;144:184-94.

33. Vaccari F, Maienza A, Miglietta F, Baronti S, Di Lonardo S, Giagnoni L, et al. Biochar stimulates plant growth but not fruit yield of processing tomato in a fertile soil. Agric Ecosyst Environ. 2015;207:163-70.

34. Tang J, Zhu W, Kookana R, Katayama A. Characteristics of biochar and its application in remediation of contaminated soil. J Biosci Bioeng. 2013:116(6):653-9.

35. Uzoma K, Inoue M, Andry H, Fujimaki H, Zahoor A, Nishihara E. Effect of cow manure biochar on maize productivity under sandy soil condition. Soil Use Manag. 2011;27(2):205-12.

36. Sorensen RB, Lamb MC. Crop yield response to increasing biochar rates. J Crop Improv. 2016;30(6):703-12.

37. Jay CN, Fitzgerald JD, Hipps NA, Atkinson CJ. Why short-term biochar application has no yield benefits: evidence from three field-grown crops. Soil Use Manag. 2015;31(2):241-50.

38. Marshall J, Muhlack R, Morton BJ, Dunnigan L, Chittleborough D, Kwong CW. Pyrolysis temperature effects on biochar-water interactions and application for improved water holding capacity in vineyard soils. Soil Syst. 2019;3(2):27.

39. Lei O, Zhang R. Effects of biochars derived from different feedstocks and pyrolysis temperatures on soil physical and hydraulic properties. J Soils Sediments. 2013;13(9):1561-72.

40. Wiersma W, van der Ploeg MJ, Sauren IJ, Stoof CR. No effect of pyrolysis temperature and feedstock type on hydraulic properties of biochar and amended sandy soil. Geoderma. 2020;364:114209.

41. Verheijen F, Jeffery S, Bastos A, Van der Velde M, Diafas I. Biochar application to soils. A critical scientific review of effects on soil properties, processes, and functions. EUR. 2010;24099:162.

42. Mekuria W, Noble A. The role of biochar in ameliorating disturbed soils and sequestering soil carbon in tropical agricultural production systems. Appl Environ Soil Sci. 2013. https://doi.org/10.1155/2013/354965.

43. Rondon MA, Lehmann J, Ramírez J, Hurtado M. Biological nitrogen fixation by common beans (Phaseolus vulgaris L.) increases with bio-char additions. Biol Fertil Soils. 2007;43(6):699-708.

44. BASTA. Biochar's added value in sustainable land use with targeted applications. 2019. http://biochar.solutions/.

45. USDA. Textural classification of soils.

46. CEE. Collaboration for Environmental Evidence. Data synthesis. 2020. https://www.environmentalevidence.org/guidelines/section-9.

47. ROSES. RepOrting standards for Systematic Evidence Syntheses. https:// www.roses-reporting.com/.

48. Hopewell S, McDonald S, Clarke MJ, Egger M. Grey literature in metaanalyses of randomized trials of health care interventions. Cochrane Database Syst Rev. 2007. https://doi.org/10.1002/14651858.MR000010. pub3.

49. Livoreil B, Glanville J, Haddaway NR, Bayliss H, Bethel A, de Lachapelle FF, et al. Systematic searching for environmental evidence using multiple tools and sources. Environ Evid. 2017:6(1):23.

50. Haddaway NR, Collins AM, Coughlin D, Kirk S. The role of Google Scholar in evidence reviews and its applicability to grey literature searching. PLoS ONE. 2015;10(9):e0138237.

51. Harzing AW. Publish or Perish 2007. https://harzing.com/resources/publi sh-or-perish

52. Sharma R, Eklund J, Barnes M, Geldmann J, Schleicher J, Pressey RL, et al. The impact of terrestrial protected areas on vegetation extent and condition: a systematic review protocol. Environ Evid. 2020;9:1-7.

53. Slodowicz D, Humbert J-Y, Arlettaz R. The relative effectiveness of seed addition methods for restoring or re-creating species rich grasslands: a systematic review protocol. Environ Evid. 2019;8(1):1-7.

54. Cohen J. Weighted kappa: nominal scale agreement provision for scaled disagreement or partial credit. Psychol Bull. 1968;70(4):213.

55. Liang B, Lehmann J, Solomon D, Kinyangi J, Grossman J, O'Neill B, et al. Black carbon increases cation exchange capacity in soils. Soil Sci Soc Am J. 2006:70(5):1719-30. 
56. Lisboa SN, Woollen E, Grundy IM, Ryan CM, Smith HE, Zorrilla-Miras P, et al. Effect of charcoal production and woodland type on soil organic carbon and total nitrogen in drylands of southern Mozambique. For Ecol Manage. 2020;457:117692.

57. Bilotta GS, Milner AM, Boyd IL. Quality assessment tools for evidence from environmental science. Environ Evid. 2014;3(1):14.

58. Evidence CfE. Collaboration for environmental evidence critical appraisal Tool Version 0.1 (Prototype). 2020.

59. Team, RC. R. A language and environment for statistical computing. Vienna: Austria; 2018.

60. Viechtbauer W. Conducting meta-analyses in $\mathrm{R}$ with the metafor package. J Stat Softw. 2010;36(3):1-48.

61. Hedges LV, Gurevitch J, Curtis PS. The meta-analysis of response ratios in experimental ecology. Ecology. 1999;80(4):1150-6.

62. Biederman LA, Harpole WS. Biochar and its effects on plant productivity and nutrient cycling: a meta-analysis. GCB Bioenergy. 2013;5(2):202-14.

63. Shackelford GE, Kelsey R, Dicks LV. Effects of cover crops on multiple ecosystem services: ten meta-analyses of data from arable farmland in California and the Mediterranean. Land Use Policy. 2019;88:104204.
64. Borenstein M, Hedges LV, Higgins JP, Rothstein HR. Introduction to metaanalysis. Amsterdam: Wiley; 2011.

65. Nobel A, Lizin S, Brouwer R, Bruns SB, Stern DI, Malina R. Are biodiversity losses valued differently when they are caused by human activities? A meta-analysis of the non-use valuation literature. Environ Res Lett. 2020;15(7):073003.

66. Havránek T, Stanley T, Doucouliagos H, Bom P, Geyer-Klingeberg J, Iwasaki I, et al. Reporting guidelines for meta-analysis in economics. J Econ Surv. 2020;34(3):469-75.

67. Egger M, Smith GD, Schneider M, Minder C. Bias in meta-analysis detected by a simple, graphical test. BMJ. 1997;315(7109):629-34.

\section{Publisher's Note}

Springer Nature remains neutral with regard to jurisdictional claims in published maps and institutional affiliations.
Ready to submit your research? Choose BMC and benefit from:

- fast, convenient online submission

- thorough peer review by experienced researchers in your field

- rapid publication on acceptance

- support for research data, including large and complex data types

- gold Open Access which fosters wider collaboration and increased citations

- maximum visibility for your research: over 100M website views per year

At BMC, research is always in progress.

Learn more biomedcentral.com/submissions 